\title{
Alba Solá García \\ Rescribir el horror. Historia y poética de la memoria en la obra de Roberto Bolaño
}

\section{Resumen}

Con los horrores del siglo XX, el mal ha caído en un vacío ontológico que lo hace ininteligible: la desemantización de su lenguaje y la atrofia de sus fórmulas niegan la posibilidad de erigir un discurso válido, sea éste en el plano moral, político o filosófico. La literatura, sin embargo, se aventura a resignificar el espacio del mal a partir de su reelaboración en la dimensión simbólica de la ficción. Roberto Bolaño reconstruye el discurso histórico chileno en Estrella distante y Nocturno de Chile, denunciando el fenómeno del mal y su reiterada aparición en la Historia; y resignificando su lenguaje a partir de una poética del ocultamiento y la sugerencia que permite visibilizar el horror y sus espacios, convirtiendo sus ficciones en documentos testimoniales que reelaboran la memoria histórica latinoamericana y reivindican sus episodios olvidados.

$$
\begin{array}{r}
\text { Palabras claves } \\
\text { la literatura y el mal, compromiso moral, horror político, memoria } \\
\text { histórica, dictadura chilena, Roberto Bolaño }
\end{array}
$$

\begin{abstract}
Due to the horrors witnessed and experienced during the XXth century, evil has fallen into an ontological void which makes it unintelligible: the semantic hollowness of its language and the atrophy of its obsolete formulas deny the possibility of building a legitimate discourse, be that moral, political or philosophical. Literature, nevertheless, dares to re-signify the space of evil from the re-elaboration of fiction's symbolic dimension. Roberto Bolaño re-articulates Chile's historical discourse in Estrella Distante and Nocturno de Chile, condemning the issue of evil and its reiterated emergence in history, re-signifying its language from the poetics of concealing and suggestion that allows to visibilize horror and its spaces, and transforming his fictions into testimonial documents
\end{abstract}


which re-elaborate the Latin-American's historical memory, claiming for its forgotten episodes.

Keywords

literature and evil, moral commitment, political horror, historical memory, Chilean dictatorship, Roberto Bolaño

Sin embargo, las sirenas poseen un arma mucho más terrible que el canto: su silencio.

Kafka

\section{La secularización del mal o la caída del mal a la banalidad}

El concepto del mal y su relación con el hombre ha tenido múltiples referentes y significados que han ido variando a lo largo de la Historia. Sus primeras construcciones, elaboradas a partir de los códigos normativos y morales colectivos que regían las primeras sociedades, sistematizadas por las doctrinas religiosas y continuadas en un imaginario de símbolos y conceptos de carácter moral, performativo y, finalmente, práctico, son hoy en día conceptos anacrónicos, casi reliquias etimológicas que no consiguen definir el fenómeno del mal en las sociedades posmodernas. La desacralización o secularización del mal, esto es, el despojamiento de toda raíz o carácter religioso y metafísico de la condición humana, que acompaña y al mismo tiempo es "efecto de los procesos de democratización, racionalización, mercantilización y desencanto” del hombre moderno, le arroja a un estado de permanente amenaza por "la trivialidad y al mismo tiempo por la atrocidad de un mundo enteramente profano en el que no habría nada más que la mecánica animal y [...] el consenso universal de la irrelevancia” (Pardo, 243).

Así, esta “racionalización positivista del mal” anula toda posibilidad de establecer una cartografía moral válida para explicar y dar sentido a la larga lista 
de horrores del siglo XX, que establece una genealogía del mal en su estado más puro: los campos de exterminio nazis y los gulags rusos; el genocidio sistematizado de comunidades enteras no sólo durante la Segunda Guerra Mundial, sino también dirigido indirectamente por gobiernos "democráticos” en las últimas décadas del siglo pasado, desde Guatemala hasta los Balcanes; el terror político de las dictaduras latinoamericanas y sus “desaparecidos;” la sofisticación armamentística, la aparición de la nefasta retórica eufemística de las “guerras humanitarias” y sus “daños colaterales” y un largo etcétera han conducido, como afirmó Steiner en su momento, a “alterar profundamente nuestro sentido de los límites de la conducta humana” (Castillo 53), caducando con ello la falacia del humanismo ilustrado y su moral burguesa y obligando al hombre posmoderno a replantearse la naturaleza de un mal desconocido hasta entonces y, sobre todo, de su infinita posibilidad. Los célebres estudios de Arendt acerca del fenómeno del nazismo marcaron un antes y un después respecto a esta nueva categoría del mal, un mal ininteligible en que la escritora veía "la lección de la terrible vaciedad del mal, ante la que las palabras y el pensamiento se sienten impotentes” (Eichmann 363).

Efectivamente, el mal ha caído en un vacío ontológico que, más que operar como una transgresión del bien, lo convierte en mera ausencia de éste; en “pura y simple irreflexión” (414), convirtiéndose en un “mal banal”, despojado de toda lógica moral y conceptual, revelándose como “el más siniestro por menos perverso” (Bilbeny 97). Esta caída del mal en la más absoluta banalidad niega cualquier intento de conceptualización o significación de sus términos y arroja al hombre contemporáneo a lo que Steiner llamaría un estado de “devaluación y deshumanización lingüísticas” que prácticamente niega la posibilidad de erigir cualquier discurso sólido, sea éste político, moral, filosófico o literario (Lenguaje 68).

Por su lado, Jean Baudrillard, en su conocido ensayo La Transparence du Mal (1990), intenta explicar este proceso de desemantización del lenguaje del mal como resultado de la multiplicación de sus metáforas, sus símbolos y sus formas 
ya sin contenido: "Rien (ni même Dieu) ne disparaît plus par la fin ou la mort, mais par prolifération, contamination, saturation et transparence, exténuation et extermination, par épidemie de simulation [...]. Plus de mode fatal de disparition, mais un mode fractal de dispersion” (12). La categoría del mal ha saturado y rebasado los márgenes de su territorio, mostrando la fragilidad de los límites que la contenían, y se ha filtrado por las grietas de lo más real, de lo más cotidiano, contaminando todas las esferas de la vida pública y privada; convirtiéndose en pura forma, puro impulso, incluso en un mero espectáculo.

Ante esta situación se plantean varias cuestiones fundamentales: ¿cómo nombrar o delimitar el fenómeno del mal en las sociedades posmodernas? ¿Cómo expresarlo, cómo codificarlo en sus sistemas de pensamiento y de representación? ¿Puede resignificarse el lenguaje del mal o estamos sumidos, como anunciaba Steiner, en "el fracaso de la palabra ante lo inhumano"? (Lenguaje 70)

La literatura ha intentado dar respuesta a ello o, al menos, ha constatado la urgencia de no perder la capacidad de nombrar los horrores que han socavado este último siglo: desde la literatura de los campos de Primo Levi o Jorge Semprún, pasando por la literatura testimonial de Rigoberta Menchú o las llamadas "novelas de dictadores”, desde Miguel Ángel Asturias hasta Augusto Roa Bastos; llegando hasta la actualidad con las ficciones de Castellanos Moya o Roberto Bolaño. Todos ellos plantean, de una u otra manera, la cuestión de cómo acercarse al horror, cómo narrar el mal y cómo gestionar sus fenómenos tanto en su nivel más íntimo como en el más colectivo; esto es, cómo dar voz a la experiencia individual del testimonio o la víctima y cómo registrar los episodios oscuros de la Historia, este "cuento corto de terror" (Bolaño, Amuleto 60).

\section{La literatura de Roberto Bolaño: un acercamiento al horror}

"Entonces yo me quedé quieto, con un dedo en la página que estaba leyendo, y pensé: qué paz. Me levanté y me asomé a la ventana: qué silencio” 
(Bolaño, Nocturno 99). Urrutia Lacroix, sacerdote y crítico literario chileno, describe así su país tras el golpe de estado de 1973. Roberto Bolaño (1953-2003) construye su novela Nocturno de Chile (2000) a partir de un único y tortuoso monólogo proferido por este personaje, que reconstruye con largas y digresivas analepsis su oscuro pasado durante una noche de fiebre en que se siente morir.

Efectivamente, este “silencio” es lo que mejor describe la situación de Chile bajo la dictadura: toques de queda y un amplio abanico de censuras en la vida y expresión públicas; exilios y represión; torturas, desapariciones y asesinatos; todo ello orquestado por un silencio fúnebre que se convierte, finalmente, en recurso narrativo de la novela. Bajo las palabras de un narrador-protagonista focalizado y tremendamente subjetivo, cuyo discurso es un esfuerzo retórico por justificar sus actos pasados frente a su propia conciencia, podemos intuir una realidad plagada de horrores que jamás nos será desvelada sino sólo sugerida mediante metáforas y elipsis; una realidad que a pesar de ser silenciada por su narrador, tendrá el mismo peso que las palabras que la ocultan.

Nocturno de Chile no es la única novela de este autor que trata de los terribles sucesos que conmocionaron el país durante la dictadura de Pinochet: su segunda obra publicada, La literatura nazi en América (1996), registra a modo de diccionario o enciclopedia de personalidades ilustres las vidas infames de personajes ficticios, y uno de ellos, Carlos Ramírez Hoffman, será reelaborado en una suerte de spin off en su siguiente obra, la novela corta Estrella distante (1996), donde Bolaño explorará la fascinante figura del poeta asesino, del criminal ilustrado; figura nacida con el nazismo y sus representantes, hombres cultivados y sensibles a las artes y a las letras y absolutamente insensibles con el género humano; personaje que ha ido reapareciendo, como apunta el autor, en los oscuros anales de la Historia.

En Amuleto (1999), Bolaño da voz a la poeta uruguaya Auxilio Lacouture, que se escondió en los baños de la Facultad de Filosofía y Letras de la Universidad Nacional Autónoma de México (UNAM) durante la ocupación de la universidad por parte del ejército y que permaneció encerrada durante más de 
quince días, entre ellos, el 2 de octubre del 1968, el día de la conocida matanza de Tlatelolco; en que el ejército nacional asesinó a sangre fría a centenares de manifestantes en la plaza de las Tres Culturas. Lacouture se convierte, pues, en testimonio indirecto de los acontecimientos y, por extensión, en visionaria de todas las masacres silenciadas de Latinoamérica.

En 2666 (2004), novela monumental publicada póstumamente, Bolaño reconstruye varios episodios de la Historia a modo de genealogía del mal que comparten como vínculo la figura de un esquivo y desconocido poeta, Archimboldi, que luchará con la Alemania nazi durante la Segunda Guerra Mundial, vagará por Europa y desaparecerá en las fronteras de Chihuahua, en Santa Teresa (Ciudad Juárez), escenario de los terribles y conocidos feminicidios. ${ }^{1}$

Por otro lado, parte de sus cuentos en Llamadas telefónicas (1997), Putas asesinas (2001) y El gaucho insufrible (2003), se sitúan también en escenarios donde el mal se reproduce y afecta invariablemente a sus personajes: "El Ojo Silva”, "El policía de las ratas" o "Detectives" responden también a una voluntad de indagación en las manifestaciones del mal en la Historia colectiva o las historias individuales del sujeto humano.

Bolaño fue reticente a la hora de confirmar una preocupación explícita por el mal en sus obras; por otro lado, su reticencia abarcaba todo intento de sintetizar su poética, de vincularlo a cualquier movimiento estético e incluso de reconocerlo como un gran escritor: polemista nato, orgullosamente humilde y desmarcado deliberadamente del ámbito académico y los medios de comunicación, nunca se definió a sí mismo sino vaga y esquivamente. Sin embargo, en sus textos no literarios, así como en las entrevistas y artículos de revistas o periódicos locales,

1 Omito deliberadamente las publicaciones póstumas en los que el autor no tuvo voluntad ni decisión de publicar: El secreto del mal (2007), El Tercer Reich (2010) y Los sinsabores del verdadero policía (2011). En su mayor parte son textos inacabados, partes omitidas de sus obras anteriores o relatos incompletos; por lo que, a razón del poco espacio del que dispongo, he decidido poner en relación con mi estudio las obras que se publicaron bajo su beneplácito, entre las que cabría incluir la casi completa 2666. 
se vislumbran más que nunca sus preocupaciones estéticas y, sobre todo, morales. En su célebre discurso de Caracas, que pronunció a raíz de la recepción del Premio Rómulo Gallegos en 1999, afirmaría que la literatura era, para él,

saber meter la cabeza en lo oscuro, saber saltar al vacío, saber que la literatura básicamente es un oficio peligroso. Correr por el borde del precipicio: a un lado el abismo sin fondo y al otro lado las caras que uno quiere, las sonrientes caras que uno quiere, y los libros, y los amigos, y la comida. (Entre paréntesis 36)

Este “abismo sin fondo”, territorio oscuro que Bolaño intenta hacer visible a través de la palabra; una palabra que circunda el agujero negro de lo inhumano en un ejercicio de observación y retransmisión permanente, parece contener todo aquello que el ser humano rechaza y que, sin embargo, siente peligrosamente cercano.

Así pues, Bolaño construye una obra en la que el mal se sucede y se literaturiza en numerosos escenarios y situaciones, trazando una suerte de cartografía que contiene sus manifestaciones situadas en espacios y en tiempos concretos. En este sentido, es importante enfatizar el sentido histórico, un sentido histórico que se sitúa más allá de la propia Historia y que trasciende la importancia del hecho, cifrado en su literatura no como dato concreto sino como fenómeno acaecido y depositado en el imaginario humano y cuyo sentido reside, precisamente, en su actualización constante a partir del discurso, de la palabra que reivindica su presencia y lo reviste de nuevos significados. En una suerte de “fenomenología del mal”, Bolaño utilizará los datos históricos para explicar la vivencia subjetiva de la historia, en un nivel individual y colectivo. La micro-historia y la macro-historia están intrincadas en un vínculo (casi) indisociable: la experiencia individual de cada sujeto se sucede en el contexto de un fenómeno histórico en el que participará, activa o pasivamente, y esta participación le influirá y modificará su suerte de forma invariable.

Por otro lado, la ecuación narrativa del escritor chileno suma a esta “fenomenología del mal” otro elemento esencial: la literatura. Los personajes envueltos en el suceder del mal tienen una estrecha vinculación con la literatura; 
poetas, escritores o críticos, comparten entre ellos sus reflexiones estéticas pero también éticas. En Bolaño encontramos, efectivamente,

una relación entre literatura -tematizada obsesivamente en el texto con personajes que la practican, publican, leen, estudian y discuten-, memoria y horror político. [...] Todos ellos enfrentan no sólo dilemas estéticos sino también éticos, se insertan en la historia para padecer las experiencias de una generación que fue joven en el momento de las dictaduras militares del continente. La narrativa de Bolaño se ubica en la encrucijada de la literatura y la historia, con la melancolía -una "extraña melancolía”- de ya no poder entregarse con fe ciega ni a una ni a otra. Se mantiene, sin embargo, la tenue posibilidad de que en el camino de reconstruir en la palabra una memoria de los hechos, sea posible descubrir o inventar aquella comunidad que se ha desbandado después del desastre. (Fischer 147)

Este “desastre”, repetido incesantemente a lo largo de todo el siglo XX en múltiples formas, reside precisamente en este acontecer del acto brutal, del horror humano o, para ser más exactos, del horror inhumano; infringido al hombre por el hombre, esta genealogía del mal que se sitúa en un abismo epistemológico y que sólo la literatura parece poder recuperar. La palabra funciona así como herramienta que consigue, si no paliar, al menos dar constancia de la perversa continuidad del acontecer del mal, en una suerte de redención o reconciliación del sujeto para con el mundo que habita y los episodios atroces y ocultos de la Historia. Estos episodios, reelaborados y reapropiados por la literatura como instrumento de denuncia de la aberración y el sinsentido, constatan la “degeneración histórica” de la misma Historia y de su discurso, en una narrativa que recrea “los sueños (o pesadillas) de la historia” (Garcés, 15).

\section{Cómo narrar el mal: la poética del ocultamiento o de la sugerencia}

Citando a Henri Lefèbvre, Steiner afirma que “el silencio está dentro del lenguaje y al mismo tiempo en sus fronteras. [...] El silencio tiene un decir distinto del decir ordinario, pero de todos modos se trata de un decir significativo" (Lenguaje 71). El silencio como unidad mínima de significado, como generador 
de sentido que articula, como la palabra, las metáforas y figuras retóricas, el desarrollo argumentativo del texto. Frente al estado de desemantización del lenguaje el escritor encuentra nuevas fórmulas para resignificar una realidad enajenada, como el propio lenguaje; una realidad que ha perdido todo vínculo entre significado y significante. El lenguaje literario, de naturaleza ya de por sí enajenada por los propios mecanismos lingüísticos de la ficción, encuentra en su aparente antítesis (la no palabra) la mejor forma de expresar o significar la realidad.

Roberto Bolaño utiliza el silencio como signo lingüístico en una poética que podríamos denominar del ocultamiento y la sugerencia. Mediante puntos de vista o focalizaciones extremadamente restringidas, a menudo encerradas dentro de uno o varios narradores-protagonista que, a su vez, articulan sus propias observaciones acerca de los hechos creando un discurso polifónico pero siempre limitado por la naturaleza de sus enunciantes, Bolaño construye un doble espacio narrativo; el referido y el sugerido, que conviven aparentemente en armonía en el mismo texto. Hay, pues, un juego con la referencialidad del lenguaje y del propio discurso literario, que niega cualquier intento de erigir un espacio objetivo pero que, sin embargo, afirma la imposibilidad del sujeto de sustraerse de los hechos que acontecen. Esta estructura de doble trama o trama y subtrama va, sin embargo, más allá de la teoría del iceberg. El silencio en Bolaño articula múltiples formas y nunca será pura ausencia de discurso, sino discurso entredicho; significado a medias: el uso de las metáforas y comparaciones, las elipsis incompletas y las anacronías serán utilizadas para develar parte de la subtrama, que irá secundando la trama de forma explícita y despuntando regularmente en ella, articulando una

cuadratura de ángulos desde los cuales se propicia una situación abyecta, se caracteriza un personaje en su oscuridad esencial o se elide un tema. Se hace énfasis en lo irrepresentable del silencio, en ese silencio que para el crítico Roland Barthes resulta más subversivo que la palabra, y que todavía va más allá de él, implica la complicidad, el susurro, la expresión a mitad del significado; o, a veces, la palabra que queda dicha, mas no confirmada. [...] La escritura propicia la posibilidad de decir el mal a través del silencio, [...] un lugar de enunciación 
tan inmenso como cualquier palabra: deja de decir lo que, paradójicamente, logra argumentar. (González 28)

En este estudio trataremos de trazar una cartografía simbólica de esta “fenomenología del mal”, es decir, cómo se articula en el espacio de la ficción el hecho histórico y la experiencia subjetiva, individual y colectiva, del acontecer del mal, analizando las obras que más se acercan a la problemática: Estrella distante y Nocturno de Chile. En estas dos obras, Bolaño construye el acontecer de un mal colectivo y la recepción en los sujetos que habitan el mismo espacio en que éste acontece. El espacio simbólico de la dictadura chilena y la ruptura epistemológica, social y moral que implica la imposición violenta de un nuevo sistema de poder y representación trasciende de su naturaleza concreta para plasmarse en el espacio abstracto del autoritarismo y del horror político; el verdadero invento del siglo XX, según Todorov. Mediante estas ficciones, Bolaño resignifica el discurso histórico oficial y da un nuevo sentido a la ficción como documento de memoria histórica.

\section{Estrella distante o el mal absoluto}

En cierta ocasión, Bolaño afirmaría que Estrella distante era un intento de “aproximación, muy modesta, al mal absoluto” (Entre paréntesis 20). La (aparente) encarnación de este mal absoluto es Carlos Wieder, poeta y piloto de avión, magnífico artista y, a la vez, cruel asesino durante la dictadura pinochetista. La obra se sitúa en un presente enunciativo que recrea, a partir de analepsis y digresiones, ciertos episodios de la vida de Arturo B. (alter ego recurrente del autor) que gravitan alrededor de Wieder, de sus poesías, de sus crímenes, de su desaparición y, finalmente, de su encuentro, mucho tiempo después. Arturo B. emplazará sus recuerdos en el Chile de Allende, en la dictadura pinochetista y, posteriormente, en la Costa Brava, recorriendo parte del camino trazado por el misterioso personaje. 
Carlos Wieder es el paradigma deformado de una visión vanguardista y visceral, tremendamente bolañana, en que el arte y la vida están intrínsecamente apegados en un mismo acontecer; se articulan a partir de un mismo imperativo moral y estético, del que Wieder representa su antítesis. A pesar de la extremada sofisticación literaria, su moral es prácticamente inexistente o, más bien, se articula en los parámetros de la barbarie más absoluta; es "un asesino que, en vez de unir la literatura a la vida, como preconiza las vanguardia, la une a la muerte” (Fischer 153). Los poemas escritos en el aire -tradicional espacio de lo sublime y lo divino- con el humo de su avioneta -emblema del progreso y de la vanguardia estética, pero también de la guerra-, encuentran su oscuro correlato con las torturas y los asesinatos a sangre fría y, a modo de despiadada performance, en las fotografías de sus víctimas agónicas o muertas que expone en el salón de su apartamento, para que sus invitados puedan “empaparse de arte nuevo” (Estrella distante 93).

El mal encuentra en Carlos Wieder la forma individual del ejecutor, del participante activo en su acontecer en un doble nivel: el abstracto y estético (en sus escritos fascistas, en sus poemas tanáticos) y el físico y material (con las torturas y asesinatos que lleva a cabo); ambos niveles conciliados en perfecta armonía en la perversa exposición de fotografías de sus víctimas, que "siguen una línea, una argumentación, una historia (cronológica, espiritual...), [unas evocan] un infierno vacío, [otras] semejan una epifanía, [en otro grupo] predomina un tono elegíaco”, (Estrella distante 97) en una suerte de atroz poesía visual.

El tratamiento de la violencia llevada a cabo por el ejecutor se revela sólo parcialmente, mediante elipsis parciales, omisiones terminológicas y metonimias que desvelan parte del efecto de un mal devastador. Así, siguiendo con la descripción de las fotografías, Bolaño sugiere ciertos aspectos de las imágenes para conseguir representar este horror, este abismo del mal en el que la palabra pierde toda posibilidad de significación: 
La mayoría eran mujeres. El escenario de las fotos casi no variaba de una a otra por lo que se deduce que es el mismo lugar. Las mujeres parecían maniquíes desmembrados, destrozados, [...] no se descarta que en un treinta por ciento de los casos estuvieran vivas en el momento de hacerles la instantánea. [...] Los símbolos son escasos pero elocuentes. [...] La foto de una joven rubia que parece desvanecerse en el aire. La foto de un dedo cortado, tirado en el suelo gris, poroso, de cemento (Estrella distante 97).

La relación con el imaginario del nazismo es evidente, y es precisamente en Estrella distante donde Bolaño ensaya más profundamente la figura del bárbaro ilustrado, conjunción entre la cultura más elevada y la inhumanidad más atroz. En este sentido, el vínculo de la barbarie con la literatura es constante a lo largo de la obra: así, la búsqueda de Wieder se realizará mediante la alianza metodológica de un detective de oficio, Abel Romero, que perseguirá a su presa mediante pistas materiales, y Arturo B., que realizará su persecución en el plano literario y documental, esto es, adentrándose en textos, artículos y testimonios que rodean el esquivo poeta. La figura de Wieder actúa en la narración como “enigma opaco, [...] no hay acceso a su monólogo interior, pronuncia apenas unas pocas frases, sólo se alcanza a tocar su presencia ausente a través de las acciones exteriores recordadas y transmitidas por otros, con el filtro del tiempo y la memoria,” (Fischer 159) convirtiéndose en un turbio espejismo, en pura ausencia, casi en fórmula narrativa que permite al autor acercarse al horror de la dictadura chilena.

La búsqueda de este enigmático personaje, aparente motivo de la narración, actúa como desencadenante y se disuelve en múltiples motivos. La infructuosa búsqueda de Stein, antítesis de Wieder, poeta y revolucionario, también desaparecido; la búsqueda de obras cortas y artículos que parecen ser de Wieder (aunque algunos no lo son) bajo excéntricos pseudónimos en anales y revistas ligadas a las neovanguardias fascistas europeas y latinoamericanas; pistas falsas o búsquedas sin un fin concreto que acabarán articulándose alrededor de una misma incógnita: ¿qué es el mal?, y, sobre todo, ¿por qué sucede? 
La figura de Wieder desaparece paulatinamente para dar paso a la indagación en nuevas formas que trascienden la concreción del individuo en sí y el espacio de la dictadura chilena y sus horrores políticos, desvinculándose de la dimensión histórica para mostrar la proliferación del mal en distintos espacios y denunciar su perversa continuidad: a través de distintos documentos y testimonios, Bolaño va ensayando distintos acercamientos al fenómeno del mal, intentando descifrar el abismo que lo circunda. Así, el mal se representa como un perverso y eterno juego de niños, en un mundo de hermanos siameses que, alternativamente, se torturan el uno al otro sin llegar jamás al asesinato o a la aniquilación, pues la muerte del otro que implicaría necesariamente la muerte de uno mismo; el doble que se abisma en el lado más oscuro de uno mismo, perpetuando un principio tanático y masoquista en que "sólo el dolor ata a la vida, sólo el dolor es capaz de revelarla” (Estrella distante104; las cursivas son mías). Y, también, encontramos la noción del mal absoluto como puro azar, terroríficamente vacío y banal; cristalizado en la imagen del "infierno como un entramado o una cadena de casualidades” (110), al que sólo puede oponerse una memoria que, precisamente por perpetuar en forma de recuerdo el horror, es "la única fuente de dolor” y, a la vez, la única dimensión libre del azar del mal (111).

El reencuentro de Arturo B. con un Wieder envejecido y vulnerable en un pueblo de la Costa Brava catalana y el develamiento, al fin, de la larga incógnita que lo rodea, es revelador: "No parecía un poeta. [...] No parecía un asesino de leyenda. No parecía el tipo que había volado a la Antártida para escribir un poema en el aire. Ni de lejos” (153). ${ }^{2}$ La mediocridad y la banalidad del sujeto en cuestión, concretizado al fin en carne y hueso, obliga al narrador a preguntarse por el propósito de la búsqueda, confirmando la disolución de Weider en un mal abstracto, colectivo, uniforme, del que éste sería un simple ejecutor entre muchos, y cuya desaparición, a pesar de contener cierta justicia poética, no implicaría la erradicación del acontecer del mal, esta "pesadilla recurrente” de la Historia (149).

2 Me gustaría introducir en relación con esto las célebres palabras de Arendt: "Me impresionó la manifiesta superficialidad del acusado, que hacía imposible vincular la incuestionable maldad de sus actos a ningún nivel más profundo de enraizamiento o motivación. Los actos fueron monstruosos, pero el responsable era totalmente corriente, del montón, ni demoníaco ni monstruoso" (La vida14). 


\title{
V. Nocturno de Chile o el silencio del mal
}

Desde la primera página de Nocturno de Chile se define la situación enunciativa que determinará el resto de la obra: la voz de Urrutia Lacroix se alza temblorosa y, a la vez, tremendamente beligerante, exigiéndole a su propio discurso que cumpla con su voluntad, su última voluntad de redimirse de los pecados de los que su propia conciencia le culpa: el silencio, la ausencia de discurso de denuncia, la complicidad del que calla aun sabiendo; forma pasiva de un mal colectivo del que Urrutia, entre muchos, será culpable.

\begin{abstract}
Ahora me muero, pero tengo muchas cosas que decir todavía. Estaba en paz conmigo mismo. Mudo y en paz. Pero de improviso surgieron las cosas. [...] Rebuscaré en el rincón de los recuerdos aquellos actos que me justifican y por lo tanto desdicen las infamias que el joven envejecido ha esparcido en mi descrédito [...]. Hay que ser responsable. [...] Uno tiene la obligación moral de ser responsable de sus actos y también de sus palabras e incluso de sus silencios, sí, de sus silencios, porque también los silencios ascienden al cielo y los oye Dios, [...] así que mucho cuidado con los silencios (11; las cursivas son mías).
\end{abstract}

El uso de un narrador focalizado permite a Bolaño construir un monólogo interior basado, precisamente, en el silencio como estrategia narrativa: el esfuerzo de Urrutia para justificar un pasado oscuro y ocultar su culpabilidad, generan un discurso que se articula mediante analepsis, digresiones y elipsis cuidadosamente elegidas; en un juego de evocación y ocultación, de sugerencias y omisiones que lo que consiguen es, precisamente, dar consistencia y visibilidad a la realidad silenciada.

Nocturno de Chile se sitúa en los últimos cincuenta años del país, para retratar sus distintas realidades a partir del filtro del sujeto enunciante. Las dimensiones tratadas, la literaria y la política, reelaboran el espacio simbólico de Estrella distante, aunque desde otros derroteros: en primer lugar, Bolaño se centrará mucho más en realzar el peso de la culpa de las élites intelectuales del país; la silenciosa complicidad de sus escritores, críticos, intelectuales y artistas, 
relatando varias anécdotas y describiendo sus actividades durante la dictadura a partir del testimonio de Urrutia. En segundo lugar, el mal se desarrollará relativamente ajeno a la realidad del sujeto enunciante, por lo que éste se vincula a la pasividad y a la permisividad; al mutismo, al fin.

Las anécdotas y los episodios que narrará el protagonista confirman, efectivamente, este silencio deliberado que acompañará a Urrutia Lacroix a lo largo de toda su vida. Sus primeros contactos con el mundo de las letras serán a través de Farewell, gran crítico literario chileno; personaje inspirado, probablemente, en el influyente y polémico crítico chileno Alone, pseudónimo de Hernán Díaz Arrieta. ${ }^{3}$ La oportunidad de asistir a las tertulias que organiza Farewell en su gran mansión de las afueras le catapultarán al mundo literario y artístico chileno, y le abrirán camino a su conversión en el crítico literario Icabache; ${ }^{4}$ no sin antes sellar una suerte de pacto mefistofélico que, a modo de metáfora, condicionará sus palabras pero, sobre todo, sus silencios: la primera vez que es invitado a la mansión de Farewell (llamada, reveladoramente, Là-bas), mientras espera el carruaje que ha de llevarlo a su destino desde una aldea perdida, escucha, horrorizado (aunque sin saber el porqué de su pavor), a unos pájaros que

parecían decir quién, quién, quién. [...] Entonces, por el fondo de la calle de tierra vi una especie de tílburi [...] que se recortaba contra el horizonte con una estampa que no puedo sino definir como demoledora, como si aquel carrioche fuera a buscar a alguien para llevarlo al infierno (17).

3 Patricia Espinosa (2001) y Christopher Domínguez Michael (2001), entre otros críticos, coinciden en identificar la figura de Farewell con la del conocido crítico chileno Alone.

4 El cura, poeta y crítico literario Icabache es en Estrella distante uno de los testimonios escritos a los que Arturo B. accede para averiguar más acerca de la figura de Carlos Wieder, del que Icabache habría hecho, sintomáticamente, una crítica bastante positiva. Como señala Ignacio Echevarría, en la totalidad de las obras de Bolaño encontramos un "principio de fractalidad" que "articula una especie de transgénero en el que se integran indistintamente poemas narrativos, relatos cortos, relatos largos, novelas cortas y novelones, [...] dando lugar a una especie de novela total": la reaparición de personajes reelaborados de una obra a otra es uno de sus síntomas (433-434). 
La culpa y la deliberada ceguera del establishment literario nacional del que Urrutia Lacroix forma parte se revela en varios pasajes: Farewell y sus soirées intelectuales y literarias en Là-bas, espacio totalmente alejado de la realidad social del país y de sus tumultuosos acontecimientos, que sólo infieren en sus vidas como pasajeras “sombras chinescas” (65); la anécdota de Salvador Reyes Figueroa, Jünger y el pintor guatemalteco atrapado en el París ocupado, hacia el cual los dos intelectuales no mostrarán la más mínima complicidad ni preocupación y, reveladoramente, la percepción de Urrutia Lacroix del golpe de Estado y la instauración de la dictadura, que describe intercalando sus hechos principales con sus lecturas de los clásicos griegos.

Que sea lo que Dios quiera, me dije. Yo voy a releer a los griegos. Empecé con Homero, como manda la tradición, y seguí con Tales de Mileto y Jenófanes de Colofón y Alcmeón de Crotona y Zenón de Elea (qué bueno era), y luego mataron a un general del ejército favorable a Allende [...] y yo leí a Esquilo y a Sófocles y a Eurípides, todas las tragedias, [...] y en Chile hubo escasez e inflación y mercado negro [...] y la Reforma Agraria expropió el fundo de Farewell y muchos otros fundos [...] y hubo atentados y yo leí a Tucídides, las largas guerras de Tucídides, los ríos y las llanuras, los vientos y las mesetas que cruzan las páginas oscurecidas por el tiempo, y los hombres de Tucídides, los hombres armados de Tucídides y los hombres desarmados, [...] y después vino el golpe de Estado, el levantamiento, el pronunciamiento militar, y bombardearon la Moneda y cuando terminó el bombardeo el presidente se suicidó y acabó todo (97-99; las cursivas son mías).

La cómplice (y, hasta cierto punto, ingenua) pasividad de Urrutia Lacroix, sin embargo, irá desapareciendo a medida que avance en su monólogo, revelando las oscuras colaboraciones que llevará a cabo con la dictadura chilena, aceptando las ofertas de dos inquietantes y desconocidos personajes, Oido y Odeim (“odio” y “miedo”). La primera de ellas le llevará a viajar por distintas iglesias europeas, donde será cómplice del uso de la cetrería y presenciará auténticas masacres de palomas y demás pájaros por parte de halcones adiestrados por los curas, con curiosos y grotescos nombres (Turco, Otelo, Jenofonte, Ta gueule, Rodrigo, Ronnie y Fiebre); y, lo que es más significativo, gozará viendo cómo “el revolotear de los estorninos se ensangrentaba, se fragmentaba y se ensangrentaba, 
y entonces el atardecer [...] se teñía de rojo intenso, [con] los movimientos como de paleta de pintor expresionista abstracto” del halcón que, con su arte siniestro y su aletear de "aspas metálicas”, (91) traía "la paz, la armonía de la naturaleza” (87). La comparación con los poemas aéreos y tanáticos de Wieder es evidente; y en una sola ocasión será el propio Urrutia el que alzará un halcón al cielo y dirigirá sus actos, aunque durante su ejecución "los pliegues de [su] sotana cubrieron [sus] ojos mientras el viento limpiaba la iglesia y sus alrededores” , y cuando recupera la vista distingue "bultos informes en el suelo, los cuerpecillos ensangrentados de varias palomas” (91).

La figura del padre Antonio, que alimentaba de “despojos” a su halcón Rodrigo, al que "la inactividad había reducido a un estado lamentable, similar en decrepitud al que lucía el padre Antonio, cuyas mejillas estaban mordidas por las dudas y el arrepentimiento a destiempo, que es el peor de los arrepentimientos” (89), se convierte en símbolo de un arrepentimiento que Urrutia se esfuerza en rechazar. A pesar de ello su imagen le acompañará, y se convertirá en una suerte de figuración de su propia conciencia atormentada: en uno de sus sueños, “antes de morir abría un ojo y me decía: esto está muy malo, amiguito. [Yo] Veía a una bandada de halcones, miles de halcones que volaban a gran altura por encima del océano Atlántico, en dirección a América” (95). Esta visión profética del sacerdote chileno remite, en un interesante cruce de referencias, a los "Halcones" de México, nombre que designaba el grupo paramilitar que participó en la masacre de Tlatelolco el 1968; ampliándose así las fronteras del suceder del horror de Chile a Latinoamérica.

La segunda oferta de Odeim y Oido será nuevamente aceptada por Urrutia, que se convertirá en profesor de marxismo para la Junta militar de la dictadura; encontrándose entre sus alumnos el mismo Pinochet. Encontramos, así, “violencia y complicidad en la ciudad letrada y en la Iglesia. Los curas entrenaban halcones para matar a las palomas y el cura Icabache enseña marxismo a Pinochet 'para comprender a los enemigos de Chile, para saber cómo piensan, para imaginar hasta dónde están dispuestos a llegar'” (Aguilar 136). 
La mansión del dictador encuentra su correlato con la casa de Farewell y ambas remiten, a modo de perverso palimpsesto, a la casa de María Canales y sus soirées literarias, en cuyo sótano Jimmy, marido de la anfitriona, tortura a sus víctimas: estos tres espacios, contenedores de un horror más o menos explícito, serán habitados por Urrutia en distintas situaciones, visibilizando su complicidad con el mal. En la casa de María Canales, el carácter oculto del hogar (espacio de lo íntimo, lo privado) se degenera hasta convertirse en centro secreto de interrogatorios, torturas y asesinatos. “Eso se supo” (Nocturno 141), pero se supo después de que todo hubiera pasado. A partir de un caso concreto (el testimonio de varios invitados extraviados que encontraban la sala de torturas del sótano) Bolaño reconstruye parte de una memoria histórica perdida; mostrándola (narrativamente) como un proceso de recuperación doloroso y difícil, en el que, poco a poco, van desvelándose los horrores que habían quedado sepultados bajo el tiempo y el silencio. Uno a uno, los invitados describen el aterrador escenario con detalles cada vez más precisos:

Vio una especie de cama metálica. Encendió la luz. Sobre el catre había un hombre desnudo, atado de muñecas y tobillos. Parecía dormido, pero esta observación es difícil de verificar, pues una venda le cubría los ojos. [...] Cerró la puerta [...] y descorrió sigilosamente el camino andado (139; las cursivas son mías).

Y luego:

Se había dado de bruces con aquel cuerpo atado sobre una cama metálica, abandonado en aquel sótano pero vivo, y [...] había cerrado la puerta sigilosamente, para no despertar al pobre hombre que reparaba en el sueño su dolor, y había desandado el camino y vuelto a la fiesta [...] y no había dicho nada (140; las cursivas son mías).

\section{Y finalmente:}

Supo que el hombre estaba vivo porque lo oyó respirar, aunque su estado físico no era bueno, pues pese a la luz deficiente vio sus heridas, sus supuraciones, [...] las partes maltratadas de su anatomía, las partes hinchadas, como si tuviera más de un hueso roto, pero respiraba, $[\ldots]$ y cerró delicadamente la puerta [...] 
apagando a sus espaldas las luces que previamente había encendido” (141; las cursivas son mías).

Y todos ellos callaron “porque tuvieron miedo;” lo asumieron “porque la rutina matiza todo horror” (142). A pesar de ello, la culpa atormenta sus conciencias, y Urrutia no deja de preguntarse: “¿Si les contara a mis amigos escritores lo que había hecho obtendría su aprobación? ¿Algunos manifestarían un rechazo absoluto por lo que había hecho? ¿Algunos comprenderían y perdonarían? ¿Sabe un hombre, siempre, lo que está bien y lo que está mal?” (113). La culpa del testimonio que, aun viendo, no se pronuncia y guarda silencio, encuentra en la última conversación de Urrutia con María Canales la forma de la confesión, pero de una confesión colectiva de un Chile que se había convertido en “el árbol de Judas, un árbol sin hojas, aparentemente muerto, pero bien enraizado todavía en la tierra negra” (138):

¿Usted sabía todo lo que hacía Jimmy? Sí, padre. ¿Y se arrepiente? Igual que todos, padre. Sentí que me faltaba el aire. [...] Después sonrió: ¿quiere ver el sótano?, dijo. La hubiera abofeteado allí mismo, en lugar de esto me senté y negué varias veces con la cabeza. [...] Aquí mató un empleado de Jimmy al funcionario español de la UNESCO. Aquí mató Jimmy a Cecilia Sánchez Poblete. A veces yo estaba viendo la tele con los niños y se iba la luz por un rato. No oíamos ningún grito, sólo la electricidad que se iba de golpe y después volvía. ¿Quiere ir a ver el sótano? [...] Apreté su mano y le sugerí que rezara. [...] No puedo rezar más de lo que ya rezo, me respondió (145; las cursivas son mías).

El epígrafe de la novela es contundente: “Quítese la peluca.” El discurso doliente y angustiado de Urrutia Lacroix busca justificar este pasado oscuro frente a su conciencia; transformada en este "joven envejecido" que “mueve los labios formulando un no inaudible” (148), “que grita sin que nadie lo escuche” (150), reclamando una respuesta que nunca obtendrá: "Poco puede uno solo contra la historia. El joven envejecido siempre ha estado solo y yo siempre he estado con la historia” (148). La historia que oculta los horrores, que acalla las voces de sus víctimas y que, sin embargo, no puede detener la verdad, la verdad que "poco a poco empieza a ascender como un cadáver. Un cadáver que sube desde el fondo del mar o desde el fondo de un barranco” (149). 


\section{Conclusiones. La ficción como testimonio y reelaboración de la memoria histórica}

El noviembre de 2010 se celebró en la Casa América de Madrid la semana del autor dedicada íntegramente a Roberto Bolaño. En una de las mesas redondas, se debatió acerca de la despolitización de la obra del autor chileno, afirmando que en ella no había signos políticos que pudieran constituirle como autor comprometido. ${ }^{5}$ Lo que propongo en este estudio es precisamente lo contrario: en Roberto Bolaño encontramos, como he intentado demostrar, una preocupación explícita por el mal, sus manifestaciones históricas y su fenomenología en el imaginario de las sociedades posmodernas.

Sus fórmulas narrativas se desmarcan, efectivamente, de las ortodoxias políticas y las ideologías de partido, aunque no por ello no dejan de remitirse a la esencia misma de la política, entendida en su sentido etimológico y literal; esto es, como espacio simbólico público y compartido, regido por una moral y unos principios éticos que faciliten la convivencia entre humanos. En este sentido, podríamos hablar de una politización depurada y esencial, cuyo compromiso se plantea en términos estrictamente morales: la cuestión fundamental para ello es cómo acercarse al horror; cómo gestionar, tanto a nivel individual como colectivo, una memoria histórica violentada y anonadada por los discursos históricos oficiales y el testimonio de la víctima, frecuentemente inasible e inenarrable.

En cierta ocasión, refiriéndose a su narrativa, Bolaño quiso remarcar lo siguiente:

5 La conferencia (24 de noviembre de 2010) a la que se hace referencia se puede ver íntegramente en http://www.casamerica.es/literatura/boom-bolano. 
En gran medida todo lo que he escrito es una carta de amor o de despedida a mi propia generación, los que nacimos en la década del cincuenta y los que escogimos en un momento dado la militancia, y entregamos lo poco que teníamos, lo mucho que teníamos, que era nuestra juventud, a una causa que creímos la más generosa de las causas del mundo y que en cierta forma lo era, pero que en realidad no lo era. De más está decir que luchamos a brazo partido, pero tuvimos jefes corruptos, líderes cobardes, [...] luchamos y pusimos toda nuestra generosidad en un ideal que hacía más de cincuenta años que estaba muerto, y algunos lo sabíamos, [...] pero igual lo hicimos, porque fuimos estúpidos y generosos, como son los jóvenes, que casi todo lo entregan y no piden nada a cambio, y ahora de esos jóvenes ya no queda nada, los que no murieron en Bolivia murieron en Argentina o en Perú, y los que sobrevivieron se fueron a morir a Chile o a México, y a los que no mataron allí los mataron después en Nicaragua, en Colombia, en El Salvador. Toda Latinoamérica está sembrada con los huesos de estos jóvenes olvidados (Entre paréntesis 37).

La necesidad de visibilizar este enorme cementerio de jóvenes sacrificados y olvidados sería uno de los motivos que llevarían al autor a indagar en el sentido de éste continente "sembrado de huesos," a reflexionar sobre los acontecimientos que desembocaron en este olvido colectivo. La obra de Bolaño es, en gran medida, una voz erigida contra este silencio, una voz en grito que quiere desenterrar estos huesos y, si no revivirlos, poder convertirlos en palabras; actualizando el vínculo entre literatura y moral no ya sólo en las intenciones de sus escritos sino en la propia narración, en la que el elemento literario tiene siempre un peso esencial.

Como hemos visto, Estrella distante y Nocturno de Chile reelaboran el espacio histórico y simbólico de la dictadura chilena y su horror político a través de la ficción, espacio del horror político que trasciende y se constituye como fenomenología del mal histórico latinoamericano. En ambas obras, la memoria articula de una u otra manera el sentido de la narración y, a la vez, se problematiza esta relación entre literatura y política. En Estrella distante, Arturo B. reconstruye la leyenda del poeta y criminal Carlos Wieder a partir de documentos y textos literarios para llegar a comprender quién era y, sobre todo, por qué hizo lo que hizo; ahondando en la figura del criminal ilustrado y problematizando el vínculo del arte y la ética. En Nocturno de Chile, su narrador se esfuerza por reescribir una memoria en la que la Historia futura y su propia 
conciencia no puedan acusarle, desenvolviéndose en el pantanoso terreno de las falacias morales y las complicidades de las élites intelectuales.

La problemática de cómo la memoria, individual y colectiva, elabora la Historia, cómo gestiona sus episodios de horror y qué partes de ella serán omitidas y, por ello, deben ser reivindicadas, es una constante temática, no sólo en las obras analizadas en el presente estudio, sino también en 2666 o Amuleto. En este sentido, podríamos afirmar que parte de la obra del autor chileno se convierte en documento moral y político de la memoria histórica latinoamericana.

En el último párrafo de Amuleto, Auxilio Lacouture contempla aturdida el sacrificio voluntario de miles de jóvenes latinoamericanos que caen en el abismo, del que sólo queda su canto en el aire:

Estaban cantando. Los niños, los jóvenes, cantaban y se dirigían hacia el abismo. Me llevé una mano a la boca, como si quisiera ahogar un grito, y adelanté la otra, los dedos temblorosos y extendidos como si pudiera tocarlos. [...] Y los oí cantar, los oigo cantar todavía, [...] muy bajito, apenas un murmullo casi inaudible, los niños más lindos de Latinoamérica, [...]. Lo único que pude hacer fue ponerme de pie, temblorosa, y escuchar hasta el último suspiro su canto, escuchar siempre su canto, porque aunque a ellos se los tragó el abismo el canto siguió en el aire del valle, en la neblina [...]. Y ese canto es nuestro amuleto (151).

El canto de los sacrificados, la voz de toda esa multitud de jóvenes latinoamericanos asesinados en la larga lista de oscuros episodios de horror histórico, se convierte en amuleto para los que siguen vivos, que deberán perpetuarlo en el recuerdo, en la palabra: con sus obras, Roberto Bolaño nos lega su particular amuleto contra el olvido de la historia, y el deber de reivindicarlo.

\section{Bibliografía}

\section{Fuentes primarias}

Bolaño, Roberto, La pista de hielo, Barcelona, Anagrama, 1993. , La literatura nazi en América, Barcelona, Seix Barral, 1996a. , Estrella distante, Barcelona, Anagrama, 1996b. 
, Llamadas telefónicas, Barcelona, Anagrama, 1997.

, Amuleto, Barcelona, Anagrama, 1999.

, Nocturno de Chile, Barcelona, Anagrama, 2000.

, Putas asesinas, Barcelona, Anagrama, 2001.

, El gaucho insufrible, Barcelona, Anagrama, 2003.

, 2666, Barcelona, Anagrama, 2004a.

, Entre paréntesis. Ensayos, artículos y discursos (1998-2003), Barcelona, Anagrama, 2004b.

\section{El mal: concepto y fenómeno}

Arendt, Hannah, [1963] Eichmann en Jerusalén. Un estudio sobre la banalidad del mal, Barcelona, Lumen, 1967.

, [1978] La vida del espíritu. El pensar, la voluntad y el juicio en la filosofía y en la política, Madrid, Centro de Estudios Constitucionales, 1984.

Baudrillard, Jean, La Transparence du Mal. Essai sur les phénomènes extrêmes, Paris, Ed. Galilée, 1990.

Bilbeny, Norbert, El idiota moral. La banalidad del mal en el siglo XX, Barcelona, Ed. Anagrama, 1993.

Pardo, José Luis, "El mal de la banalidad”, en Duque, Félix, El mal: irradiación y fascinación, Barcelona, Ed. del Serbal, 1993.

Steiner, George, [1971] En el castillo de Barba Azul. Aproximación a un nuevo concepto de cultura, Barcelona, Ed. Gedisa, 1991.

, [1976] Lenguaje y silencio. Ensayos sobre la literatura, el lenguaje y lo inhumano, Barcelona, Ed. Gedisa, 2003.

\section{Obra crítica sobre Bolaño:}

Aguilar, Paula, "Pobre memoria la mía. Literatura y melancolía en el contexto de la postdictadura chilena”, en Paz Soldán, Edmundo y Faverón Patriau, Gustavo (eds.), Bolaño Salvaje, Barcelona, Ed. Candaya, 2008, pp. 127144.

Domínguez Michael, Christopher, "Pinochet estudia marxismo”, en la revista Letras Libres, Ciudad de México, mayo del 2001.

Echevarría, Ignacio, “Bolaño extraterritorial”, en Paz Soldán, Edmundo y Faverón Patriau, Gustavo (eds.), Bolaño Salvaje, Barcelona, Ed. Candaya, 2008, pp. 431-446.

Espinosa, Patricia, "Vericuetos de una conciencia tenebrosa", en la revista Rocinante, Santiago de Chile, mayo 2001. 
Fischer, María Luísa, "La memoria de las historias en Estrella distante de Roberto Bolaño”, en Paz Soldán, Edmundo y Faverón Patriau, Gustavo (eds.), Bolaño Salvaje, Barcelona, Ed. Candaya, 2008, pp. 145-162.

Garcés, Gonzalo, "Nocturno de Chile o el sueño de la Historia”, en la revista Quimera, núm. 241, marzo del 2004, Barcelona.

González, Daniuska, "El silencio del mal”, en la revista Quimera, núm. 241, marzo del 2004, Barcelona. 